\title{
"Más poéticas que pedagógicas palabras": Gerardo Diego y el curso de historia de la música para piano en el Ateneo de Soria (1921) ${ }^{1}$
}

\author{
"More poetic than pedagogical words": Gerardo \\ Diego and the Course on the History of Piano Music \\ at the Ateneo de Soria (1921)
}

La excepcional pasión por la música de la que Gerardo Diego hizo gala a lo largo de toda su vida dio lugar a una ingente producción poética, crítica y ensayística, además de notas al programa, colaboraciones radiofónicas y un sinfin de conferencias-concierto. Entre febrero y mayo de 1921, durante su primer curso como catedrático de Literatura, Diego llevó a cabo el ambicioso proyecto de explicar e interpretar doscientos años de literatura pianística ante los socios del Ateneo de Soria en trece conferencias-concierto. Este "Curso de historia de la música para piano" fue, sin duda, su primer proyecto de gran envergadura. En consecuencia, el presente artículo valora la realización de este curso como una muestra inequívoca del talento precoz y exquisito bagaje musical que el joven Gerardo Diego forjó durante sus años formativos en Santander, Bilbao y Madrid y como un inusitado ejemplo de la presencia de agendas musicales cosmopolitas en un contexto local gracias a la generosa contribución de valiosos individuos.

Palabras clave: Gerardo Diego, Ateneo de Soria, conferencias-concierto, años veinte, historia de la música para piano, música española, vanguardia.

Gerardo Diego's lifetime passion for music gave rise to an enormous output of poems, criticism and essays as well as programme notes, radio collaborations and an endless number of concert-lectures. Between February and May 1921, during his first year as Professor of Spanish Literature, Diego embarked on an ambitious project of explaining and performing two hundred years of piano literature for the members of the Ateneo of Soria in thirteen illustrated lectures. This "Course on the History of Piano Music" was, undoubtedly, his first large-scale project. This article thus views this course as a clear demonstration of the young Gerardo Diego's precocious musical talent and excellent knowledge gained during his formative years in Santander, Bilbao and Madrid, and as a rare example of cosmopolitan musical agendas present in a local context due to the generous contribution of wealthy individuals.

Keywords: Gerardo Diego, Ateneo de Soria, illustrated lectures, 1920s, history of piano music, Spanish music, avant-garde.

${ }^{1}$ Una primera versión de este artículo, bajo el título "Un legado del músico-poeta: el curso de historia de la música para piano de Gerardo Diego en el Ateneo de Soria", fue presentada por la autora en el ciclo de conferencias del XXII Festival Otoño Musical Soriano, 18-9-2014. Quisiera agradecer a Adolfo Sainz, presidente del Círculo Amistad Numancia de Soria, su ayuda en los inicios de esta investigación, y a Juan Antonio Gómez Barrera el haber compartido conmigo su valiosa investigación sobre el Ateneo de Soria en la prensa local. 
Gerardo Diego Cendoya (Santander 1896; Madrid 1987) fue una figura fundamental en la cultura española del siglo XX. Músico, ensayista y poeta, fue un intelectual en el sentido más amplio de la palabra. Como miembro de la llamada "Generación del 27", Gerardo Diego comparte un lugar en la historia junto a nombres de la talla de Rafael Alberti,Vicente Aleixandre, Dámaso Alonso, Luis Cernuda o Federico García Lorca². Su producción literaria es justamente valorada y apreciada y su excepcional pasión por la música, a la que dedicó no solo poemas, sino también notas al programa, artículos y ensayos, conferencias-concierto e importantes colaboraciones radiofónicas para RNE, ha sido en los últimos años objeto de alentadores trabajos $^{3}$ e inspiración para ciclos de conciertos que destacan la privilegiada relación que Gerardo Diego mantuvo con la música de su tiempo ${ }^{4}$.

Uno de los primeros grandes retos de su vocación musical y excepcional calidad como pianista fue, precisamente, la serie de trece conferenciasconcierto que conformaron su "Curso de historia de la música para piano" impartido en el Ateneo de Soria en $1921^{5}$. Estas sesiones no fueron una rareza dentro del ambiente musical y concertístico del primer tercio del siglo $\mathrm{XX}$ siempre que las enmarquemos dentro del contexto del concierto

\footnotetext{
2 Entre los diversos estudios publicados sobre la "Generación del 27" y sus principales protagonistas destacan, Francisco Narbona: Sevilla, Góngora y la Generación del 27: crónica y protagonistas, Sevilla, Guadalquivir Ediciones, 1997, por revisitar su evento fundacional y la amplia selección de antologías poéticas, epistolares y documentales. Véase la antología documental Juan Manuel Rozas (ed.):

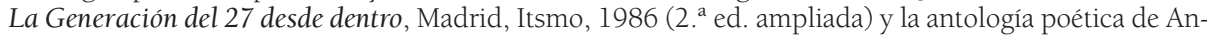
drés Soria Olmedo: Las vanguardias y la generación del 27, Madrid, Visor-Centro para la Edición de los Clásicos Españoles, 2007.

${ }^{3}$ Destacan Anselmo López Castro: "Gerardo Diego, músico y poeta", Cuadernos Hispanoamericanos, 553-554, julio-agosto 1996, pp. 23-58; Ana Benavides: "Gerardo Diego. Un artista de doble vocación”, Música y cultura en la Edad de Plata, 1915-1939, María Nagore Ferrer, Leticia Sánchez de Andrés y Elena Torres (coords.), Madrid, ICCMU, 2009, pp. 97-110; id.: Gerardo Diego y la música, Santander, Universidad de Cantabria, 2011, y las diversas contribuciones de Ramón Sánchez Ochoa, particularmente R. Sánchez Ochoa: Poesía de lo imposible: Gerardo Diego y la música de su tiempo, Valencia-Santander, Pre-Textos-Fundación Gerardo Diego, 2014.

${ }^{4}$ En 1990 se celebró el ciclo "Músicas para Gerardo Diego" en la Fundación Juan March de Madrid y con la colaboración de Cultural Rioja, en https://recursos.march.es/culturales/documentos/conciertos/ cc164.pdf (consulta 8-6-2018) y recientemente se ha programado el ciclo "Gerardo Diego y la música. Homenaje al poeta músico", organizado por la Fundación Gerardo Diego con la colaboración del Aula de Letras de la Universidad de Cantabria y el Ateneo de Santander. Este último ciclo se celebró en Santander los días 3, 5, 10 y 17 de octubre de 2017 y en la Real Academia de Bellas Artes de San Fernando, http://www.realacademiabellasartessanfernando.com/es/actividades/cursos-y-conferencias/ gerardo-diego-y-la-musicahomenaje-al-poeta-musico (consulta: 8-6-2018).

${ }^{5}$ Las publicaciones citadas sobre Gerardo Diego y la música mencionan, de modo anecdótico, la realización de estas conferencias-concierto. Tres autores sorianos han tratado en mayor o menor medida estas sesiones: Juan Antonio Gómez Barrera: El Ateneo de Soria. Medio siglo de cultura y reivindicación social (1883-1936), Soria, Soria Edita, 2006, pp. 113-122, quien realiza un exhaustivo estudio de las reseñas aportadas por la prensa local; César Ibáñez París: "Gerardo Diego en la prensa soriana (19201923)", Diario de Soria, 3-6-1992, p. 7 y Jesús Ángel León: "Las conferencias musicales de Gerardo Diego" [s.]. - documento enviado por Gómez Barrera a la autora, que analiza brevemente el programa de las conferencias-concierto sorianas de Diego.
} 
histórico que, con especial hincapié en el recital pianístico y desde el siglo XIX, había inundado la agenda internacional ${ }^{6}$. Pero representaron un hito cultural de primer orden por dos motivos fundamentales. En primer lugar, por la ambición musical del proyecto en sí mismo. En apenas tres meses y medio y con frecuencia más o menos semanal (véase el Apéndice 1), Gerardo Diego, que no era un músico dedicado en exclusiva a su carrera pianística, presentó al público soriano un programa que abarcaba un repertorio pianístico desde la conocida como "Fuga del Gato"-Sonata K. 30- de Domenico Scarlatti hasta los Tres preludios para piano de Adolfo Salazar, publicados por Chester Music en Londres en 1919 y recibidos por Diego en Soria cuando todavía era un recién llegado y se encontraba sin piano "ni amistades suficientes para utilizar aún los ajenos" lugar, estas trece conferencias-concierto supusieron un verdadero acicate en la Soria de la época, una ciudad provinciana de corte conservador que acababa de refundar su Ateneo, que apenas sobrepasaba los 7.500 habitantes $^{8}$ y cuya actividad musical, más allá de la presencia de las bandas de música o rondallas populares, se limitaba a los bailes y las veladas pianísticas celebradas en los salones del Casino y cuyo repertorio se componía fundamentalmente de arreglos de grandes números de ópera y zarzuela y un progresivo incremento de la música de cámara y arreglos a dos pianos o piano a cuatro manos del repertorio sinfónico'

\footnotetext{
6 Desde las "Historical Soirées" impartidas por Ignaz Moscheles en Londres entre 1837 y 1846, el fenómeno del concierto histórico como fórmula para legitimar el canon musical supuso una revolución en la práctica concertística de las capitales europeas, con especial impacto en el ámbito parisino. Véase Katharine Ellis: Interpreting the Musical Past, Oxford, Oxford University Press, 2005, pp. 40-44; William Webber, The Great Transformation of Musical Taste. Concert Programming from Haydn to Brahms, Cambridge, Cambridge University Press, 2008, pp. 235-272; Mark Kroll: Ignaz Moscheles and the changing world of musical Europe, Woodbridge, Boydell, 2014, pp. 284-300; y, en el caso de pianistas españoles a comienzos del siglo XX, Màrius Bernadó: Introducción y notas a "París 1905. Viñes, una historia del piano. Cuatro conciertos históricos". Ciclo de los Miércoles, Madrid, Fundación Juan March, 2015 y Sonia Gonzalo Delgado: "¿Un nuevo repertorio? La inclusión de los clavecinistas ibéricos del siglo XVIII en la actividad concertística española. La figura de Joaquín Nin", Revista de Musicología, XXXIX, n. ${ }^{\circ} 1,2016$, pp. 173-209.

${ }^{7}$ Carta de Gerardo Diego a Adolfo Salazar. Soria, 25-4-1920. Consuelo Carredano (ed.): Adolfo Salazar. Epistolario 1912- 1958, Madrid, Publicaciones de la Residencia de Estudiantes, 2008, p. 95.

8 Según el Censo de 1920 del INE, Soria capital contaba con una población de 7.619 personas de hecho y 7.703 de derecho. (http://www.ine.es/inebaseweb/treeNavigation.do?tn=82705\&tns=85414\#85414 consulta 8-6-2018).

${ }^{9}$ Francisca García Redondo: "La vida musical del Círculo Amistad Numancia", Actas del CL Aniversario del Círculo Amistad Numancia, Soria, Exma. Diputación Provincial de Soria, 2000, pp. 81-98; Myriam Núñez Jiménez: "La vida musical en la ciudad de Soria a través de la prensa: 1900-1910", tesis doctoral inédita, Universidad de Valladolid, 2014, (http://uvadoc.uva.es/handle/10324/6463, consulta 8-6-2018) y José Ignacio Palacios Sanz, Ricardo Martín de la Guardia: "Casinos y espacios de recreo para la música: el caso de la ciudad de Soria (1848-1936)", Studia historica. Historia contemporánea, 35, 2017, pp. 317-337; 325-326. Estas publicaciones hacen hincapié en la importancia de los diferentes modelos asociativos surgidos desde mediados del siglo XIX en la capital para la práctica musical, cuyo epicentro es el piano ante la falta de una actividad sinfónica o de cámara.
} 
Este artículo pretende valorar el legado musical que Gerardo Diego dejó en la ciudad de Soria a través de, por un lado, el análisis del contexto sociocultural en el que se enmarcaron estas conferencias-concierto y, por otro, del estudio comparado entre el repertorio interpretado por Diego y las diferentes tendencias del momento y el bagaje musical adquirido en sus años de juventud. Ante la falta del programa original ${ }^{10}$, las reseñas anónimas aparecidas en la prensa local son nuestra fuente fundamental ${ }^{11}$, las cuales informan, en la mayoría de los casos de manera exclusiva, sobre el programa interpretado y reproducen, en gran medida, las palabras del propio Diego al respecto del repertorio y compositores elegidos. Más allá del valor intrínseco para la historia cultural y musical de la ciudad, estas sesiones pueden considerarse un inusitado ejemplo de la presencia de agendas musicales cosmopolitas en un contexto local gracias a la generosa contribución de valiosos individuos.

\section{Gerardo Diego y el Ateneo de Soria}

Soria fue el primer destino de Gerardo Diego tras aprobar las oposiciones a las cátedras de Lengua y Literatura en los Institutos de Gijón y Soria en $1920^{12}$. El tribunal presidido por Emilia Pardo Bazán le otorgó un segundo puesto y el 21 de abril de 1920 tomó posesión de la cátedra en el entonces Instituto General y Técnico de Soria -hoy Instituto Antonio Machado- al que trece años antes, en 1907, había llegado precisamente Antonio Machado como catedrático de Francés. El clima cultural que encontró a su llegada, poco frecuente en una "mínima ciudad española" tal y como Diego la calificaba ${ }^{13}$, con epicentro en el Casino y en el recién refundado Ateneo, favoreció su implicación en las actividades culturales de la ciudad hasta que marchó en mayo de 1922 a Gijón, su siguiente destino como docente.

El Ateneo de Soria desarrolló su actividad entre 1883 y el inicio de la Guerra Civil de manera intermitente, en cuatro etapas. Gómez Barrera

\footnotetext{
${ }^{10}$ A pesar de que Gerardo Diego hizo referencia en diversas ocasiones a un folleto editado por el Ateneo de Soria, este no ha sido localizado y tampoco se conserva en el Archivo Personal de Gerardo Diego.

${ }^{11} \mathrm{El}$ acceso a los fondos hemerográficos locales de la época (La Idea, El Avisador Numantino [AvN], El Porvenir Castellano $[\mathrm{PoC}]$ y Noticiero de Soria $[\mathrm{NoS}]$ ) se ha realizado a través de la Biblioteca Virtual de Prensa Histórica.

${ }_{12}^{12}$ Gaceta de Madrid, 106, 15-4-1920, pp. 166-167.

${ }^{13}$ Gerardo Diego: "Ángel del Río en Soria", Revista Hispánica Moderna, XXXI /1-4, 1965, pp. 121 123. Reproducido en Francisco Javier Díez de Revenga (ed.): Gerardo Diego. Obras completas. Prosa. Tomo IV. Memoria de un poeta (volumen 1), Madrid, Alfaguara, 1997, pp. 244-249. Gerardo Diego recuerda en este artículo cómo al poco tiempo de su llegada encontró en la "peña del Casino de Numancia" un selecto grupo de amigos con los que compartía aficiones poéticas, literarias y artísticas.
} 
establece los orígenes del Ateneo de Soria en 1883, adscrito al Casino de Numancia y con Nicolás Rabal como presidente. Entre 1896 y 1897, y con el filósofo Antonio Pérez de la Mata como figura fundamental, se inició una segunda etapa. Un tercer intento por consolidar el Ateneo soriano se llevó a cabo entre 1901 y 1902 y, finalmente, se refundó en 1918 para realizar una actividad cultural ininterrumpida hasta el inicio de la Guerra Civil ${ }^{14}$. Su creación se enmarca, por tanto, dentro de la proliferación de Ateneos culturales entre los años ochenta del siglo XIX y la II República que, bien impulsados por la burguesía o las clases trabajadoras, se alzaron como centros de encuentro y de debate, fundamentales para la difusión de la cultura y la ciencia, así como garantes de celebraciones y reivindicaciones locales. En definitiva, fueron epicentros de formación que elevaron el nivel intelectual de las ciudades ${ }^{15}$. El Ateneo de Soria, heredero de la tradición liberal burguesa, tuvo como su etapa más prolongada y prolífica la iniciada en 1918 por un grupo de intelectuales locales de la misma generación que Gerardo Diego. Entre los refundadores del Ateneo se encontraban el archivero y bibliotecario José Tudela de la Orden (1890;1973), el joven director del Museo Numantino Blas Taracena Aguirre (1895; 1951), el inspector de Primera Enseñanza Gervasio Manrique Hernández (1891; 1978) y el abogado, periodista y gran tertuliano Mariano Granados Aguirre $(1897 ; 1972)$. Entre sus socios también figuraban Bernabé Herrero $(1903 ; 1957)$ - poeta, funcionario de Correos y, más tarde, juez y profesor de español exiliado y, sobre todo, gran amigo de Gerardo Diego-, Alfredo Gómez Robledo $(1875 ; 1953)$-sucesor de Antonio Machado en la cátedra de Francés del Instituto General y Técnico, además de Presidente del Ateneo entre 1919 y 1932- y el abad Santiago Gómez Santacruz (1869; 1949), a quien Diego conoció nada más llegar a Soria en la pensión "Casa de las Isidras" donde se instalón ${ }^{16}$, situada en la céntrica calle del Collado n. ${ }^{\circ} 46$, a escasos pasos del Casino de la capital.

Gómez Barrera afirma que el ciclo de conferencias inaugurado el 16 de marzo de 1918 e impartido en el Casino de Numancia por José Tudela, Blas Taracena y el abad Santiago Gómez Santacruz entre otros, fue el preámbulo de un Ateneo todavía no refundado ${ }^{17}$. La cuarta etapa se inició finalmente el 12 de mayo de 1918 con 70 socios y las siguientes pretensiones: "1) satisfacer la curiosidad intelectual de sus asociados, 2) investigar o hacer un inventario de todas las riquezas espirituales y materiales que tenemos en

${ }^{14} \mathrm{~J}$. A. Gómez Barrera: El Ateneo de Soria.

${ }^{15}$ Para una visión general de los objetivos y evolución histórica de los Ateneos liberales en España desde la creación del Ateneo de Madrid en 1835, Francisco Villacorta Baños: "Los Ateneos liberales: política, cultura y sociabilidad intelectual", Hispania, LXIII/2, n. ${ }^{\circ}$ 214, 2003, pp. 415-442.

${ }^{16}$ Antonio Gallego Morell: Vida y poesía de Gerardo Diego, Barcelona, Aedos, 1956, p. 38.

${ }^{17}$ J. A. Gómez Barrera: El Ateneo de Soria..., pp. 68-69. 
la provincia y 3) de divulgación, para elevar el nivel cultural del pueblo"18. Financiado gracias al pago de cuotas mensuales y a donaciones y préstamos, el Ateneo tuvo como piedra angular la creación de una biblioteca y la organización de conciertos, veladas teatrales y ciclos de conferencias que, hasta 1925, se celebraron en el Salón-Teatro del Casino de la capital. La conferencia pública fue la verdadera sabia ateneísta según Villacorta Baños $\mathrm{y}^{19}$, en un centro semiurbano como Soria, que no contaba con centros ni academias oficiales o cátedras universitarias - más allá de la Escuela Normal de Maestros-, supuso una verdadera aportación intelectual a través de figuras fundamentales del panorama científico y cultural del país.

El 17 de agosto de 1918 se inició un segundo ciclo con la presencia del arqueólogo José Ramón Mélida y Alienari (1856; 1933) -director del Museo Arqueológico Nacional entre 1916 y 1930 así como director de las excavaciones de Numancia y Mérida ${ }^{20}-$ y, entre las novedades del curso 1919-1920, el Ateneo incluyó cursos de idiomas. La primera velada musical que Gerardo Diego protagonizó en Soria, apenas cuatro semanas después de su llegada a la capital castellana, se organizó dentro de estos ciclos de conferencias. Precedido de dos charlas sobre pintura española centradas en El Greco y Goya y celebradas en el Salón-Teatro del Casino ${ }^{21}$, Diego fue presentado ante el público soriano en su doble personalidad de literato y músico.

El sábado 22 de mayo de 1920 Gerardo Diego interpretó una selección de Nocturnos de Frédéric Chopin, como refleja la invitación elaborada por el Ateneo de Soria para la ocasión (Figuras 1 y 2) ${ }^{22}$, en el piano Steinway \& Sons adquirido por el Casino en 1886 y que aún hoy se encuentra en condiciones de uso en el renombrado "Salón Gerardo Diego" del Casino de la capital.

${ }_{18}$ J. A. Gómez Barrera: El Ateneo de Soria..., pp. 74-76. Barrera apunta el éxito de la iniciativa al registrar 117 socios en el primer listado para el curso 1918-1919 y el pago de una cuota de 1,50 pesetas mensuales además de la organización del Ateneo en ocho secciones temáticas.

${ }^{19}$ F. Villacorta Baños: "Los ateneos liberales...", pp. 429-430.

${ }^{20}$ La conferencia de Ramón Mélida y Alienari se centró en la ermita de San Baudelio de Berlanga, J. A. Gómez Barrera: El Ateneo de Soria..., p. 81.

${ }^{21}$ José Tudela de la Orden impartió la conferencia "La Pintura Española: El Greco" el viernes 30 de abril de 1920 y Joaquín Alcañiz, profesor de dibujo de la Escuela Normal, impartió la conferencia "La Pintura Española: Goya" el lunes 17 de mayo de 1920. Véase J. A. Gómez Barrera: El Ateneo de Soria..., p. 102.

${ }^{22}$ Gerardo Diego interpretó los Nocturnos (V), op. 15, n. ${ }^{\circ} 2$ en Fa sostenido mayor (XI), op. 37 n. ${ }^{\circ}$ 1 en Sol menor (XII), op. 37 n. ${ }^{\circ} 2$ en sol mayor (XIV), op. 48 n. ${ }^{\circ} 2$ en Fa sostenido menor, (XV), op. 55, n. ${ }^{\circ} 1$ en Fa menor y (XIX), op. 72 , n. ${ }^{\circ} 1$ publicado póstumo en Mi menor. El programa fue también publicado en La Idea, Soria, 23-5-1921, p. 3. Quisiera agradecer a Elena Diego Marin el acceso y el permiso de reproducción de esta invitación. 


\section{Ateneo de Soria.}

La Junta de Gobierno de este Ateneo tiene el honor de invitar a $\gamma$. a la velada que a cargo de

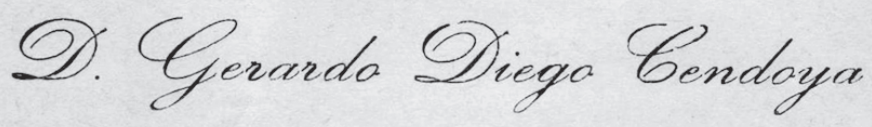

se celebrará en el Salón Srincipat del Casino de Numancia el próximo sábado 22 del actual a las 7 y media de la tarde con arreglo at siguiente programa.

Soria 21 de Mayo de 1920.

है Presidente,

Alfredo Gòmez Robledo

Figura 1. Invitación. (Archivo personal de Gerardo Diego) 


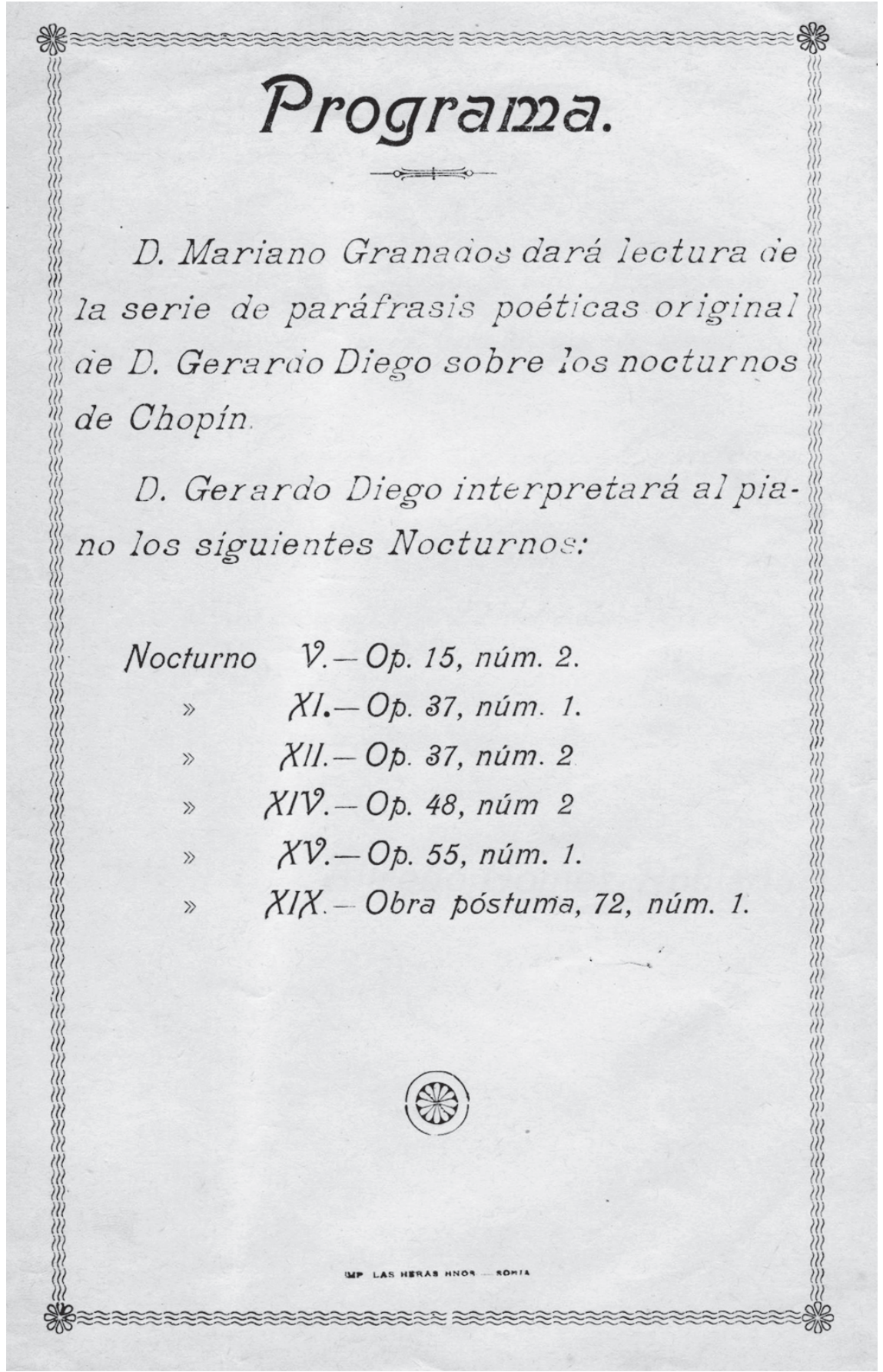

Figura 2. Programa. (Archivo personal de Gerardo Diego) 
Mariano Granados fue el principal impulsor de esta velada además de una de las primeras amistades que el músico-poeta encontró en Soria. Granados acompañó la interpretación de Diego con la lectura de las correspondientes paráfrasis a los Nocturnos de Chopin, entonces inéditas y que el literato santanderino publicó por primera vez en $1963^{23}$. Asimismo, preludió la velada, según El Porvenir Castellano, con "algunas consideraciones estéticas sobre las relaciones de unas artes con otras, de la poesía con la música, especialmente, para explicar el motivo de las paráfrasis poéticas sobre los nocturnos de Chopin de Gerardo Diego"24. Escritas en su mayoría en 1918, estas Paráfrasis son obra de juventud empapada, a juicio de Hernández Sánchez, del "romanticismo juvenil traspasado de estética simbolista"25.

Por entonces, mis versos no pretendían público alguno. Únicamente un par de amigos a quien leérselos en la intimidad; leales amigos sinceros de afecto y consejo. No me atrevía yo todavía a imprimir mis versos, escritos con tanta insegura timidez como ilusión poética. Mi primera poesía impresa en una revista lo fue por decisión ajena y para mí sorprendente y ruborizante ${ }^{26}$.

Esa impresión "ruborizante" bien pudo ser, como apuntó Gómez Barrera, la publicación de la "Paráfrasis poética del Nocturno XV de Chopin" en la portada de El Provenir Castellano el 31 de mayo de 192027 pues, por aquel entonces, las Paráfrasis no eran sino para "decirme a mí mismo en voz baja lo que la música de los nocturnos me sugería cuando tocaba el piano"28. El éxito de esta velada dedicada a los Nocturnos de Chopin fue la razón por la que, al año siguiente, entre el 15 de febrero y el 30 de mayo, Gerardo Diego se embarcó en la tarea de explicar al público soriano la "Historia de la música para piano" en trece conferencias-concierto. Pero, además, en 1922 colaboró en las primeras jornadas teatrales de la ciudad -impartiendo la sesión introductoria de la segunda jornada dedicada a Lope de Vega ${ }^{29}$ - y en la publicación local La Cotorra que, según Díez de

\footnotetext{
${ }^{23}$ Gerardo Diego: Nocturnos de Chopin, Madrid, Bullón, 1963.

24 "Gerardo Diego Cendoya en el Ateneo de Soria", PoC, Soria, 24-5-1921, p. 2.

${ }^{25}$ Mario Hernández Sánchez: "Pregerardo Antediego: Ofrenda a Federico Chopin”, Gerardo Diego y la Vanguardia Hispánica - Actas del Congreso Internacional Iberoamérica y España en la génesis de la Vanguardia Hispánica. Cáceres, 11-14 de mayo de 1992, José Luis Bernal (ed.), Universidad de Extremadura, 1993, pp. 25-42; 29.

26 G. Diego: Nocturnos de Chopin..., p. 10

27 G. Diego Cendoya: "Paráfrasis poética del Nocturno XV de Chopin", PoC, Soria, 31-5-1920, p. 1. Véase también J. A. Gómez Barrera: El Ateneo de Soria..., pp. 114-115.

${ }^{28}$ G. Diego: Nocturnos de Chopin..., p. 12.

${ }^{29}$ El Ateneo de Soria programó la "Historia del Teatro Español - Serie de representaciones" en seis sesiones que abarcaban desde Juan del Encina al Duque de Rivas. El folleto editado por el Ateneo se conserva en la Biblioteca Pública de Soria bajo la signatura SS-F C-18. No obstante, solo se llevaron a cabo las tres primeras sesiones, J. A. Gómez Barrera: El Ateneo de Soria..., p. 129.
} 
Revenga, le supuso una experiencia capital a la hora de fundar las conocidas revistas santanderinas Carmen y Lola en $1927^{30}$.

\section{Curso de "Historia de la música para piano"}

En mi primer invierno en Soria, el de 1920-1921, yo organicé, para divertirme yo sobre todo y de paso para distraer a los amigos, alumnos, alumnas, profesores, socios del Casino, una serie de 14 conferencias de historia de la música de piano, de la que quedan con las benévolas reseñas de la prensa local, los programas en un folleto editado por el Ateneo de Soria. Desde Frescobaldi a Bartók, Falla, el Ravel de última hora y Adolfo Salazar figuraba poco más o menos toda la nómina de la historia universal de la música tocada por mis pecadoras manos luchando contra el frío de la sala de actos y explicada por mis entusiastas y más poéticas que pedagógicas palabras ${ }^{31}$.

Apenas tres días antes de iniciar este ciclo, el 12 de febrero, Diego escribió a Manuel de Falla que su "Curso de Historia (muy sintética) de la Música pianística; lecturas y comentarios" estaba pensado "con un criterio vulgarizador, único modo de que el público saque algo en limpio y único modo también de que puede intentarlo un profano atrevido como yo" 32 El fin divulgador de este curso, celebrado en el Salón-Teatro del Casino y programado dentro de los ciclos de conferencias, coincidía plenamente con la política cultural implementada por el Ateneo de Soria en su reciente refundación. De este modo, la prensa soriana anunció, a comienzos de febrero de 1921, que "el ilustrado catedrático D. Gerardo Diego, que amablemente aceptó la invitación hecha por su Junta Directiva, ha organizado un 'Curso de historia de la música para piano' [...], en 13 sesiones, desarrollará cronológicamente la historia de la música desde los instrumentos precursores del piano hasta los últimos autores contemporáneos" 33 , interpretando al piano las obras anunciadas y rodeándolas "de unos comentarios estéticos, históricos y analíticos" 34 . La singularidad que supuso el hecho de que un literato abordase la tarea de impartir una "Historia de la música para piano" y, sobre todo, que lo hiciese en una ciudad como Soria, fue apuntada con posterioridad por el propio Adolfo Salazar en el periódico El Sol:

\footnotetext{
${ }^{30}$ Francisco Javier Díez de Revenga: "La Revista La Cotorra (Soria, 1922) en la primavera temprana de Gerardo Diego", Archivum. Revista de la Facultad de Filología, 48-49, 1998-99, pp. 195-217; 196. Las revistas Carmen y Lola, junto a otras revistas surgidas por iniciativa de los miembros de la Generación del 27, son esenciales para comprender la poesía hispana de los años veinte.

${ }^{31}$ G. Diego: "Aquel Carnaval en Soria", Arriba, 21-2-1975, Gerardo Diego. Obras completas. Tomo IV..., pp. 336-338; 336-337.

32 Carta de Gerardo Diego a Manuel de Falla. Soria, 12-2-1921. Federico Sopeña (ed.): Gerardo Diego-Manuel de Falla. Correspondencia, Santander, Fundación Marcelino Botín, 1988, p. 12.

33 "Ateneo de Soria", AvN, Soria, 9-2-1921, p. 3; "Ateneo de Soria", NoS, 11-2-1921, p. 2; "Noticias generales. Ateneo de Soria", PoC, Soria, 14-2-1921, p. 2

${ }^{34}$ Carta de Gerardo Diego a Manuel de Falla. Soria, 11-3-1921. F. Sopeña (ed.): Gerardo Diego-Manuel de Falla..., p. 21.
} 
a la par de ser uno de los poetas de nuevo cuño y más rico metal, es un pianista excelente que cultiva "toda" la historia de esa literatura musical [...]. Gerardo Diego, poeta, es catedrático de Literatura. Músico, ha dado en la ciudad en que profesa (Soria), un curso de historia de música para piano. (¿Cuántas rarezas juntas van ya?). Su curso estuvo dividido en trece sesiones de las que él mismo fue intérprete ${ }^{35}$.

El Apéndice 1 recoge los trece programas que ilustran un recorrido por doscientos años de literatura pianística desde Frescobaldi y Scarlatti a las últimas músicas europeas incluyendo el Ragtime de Stravinsky y À Claude Debussy de Gian Francesco Malipiero ${ }^{36}$, sin olvidar la modernidad que todavía representaban los Cuadros de una exposición de Mussorgsky o los Preludios de Scriabin. Pero, sin duda, la interpretación de los mencionados Tres preludios de Adolfo Salazar y de la versión para piano de la "Danza ritual del fuego" de El Amor Brujo, cuya copia fue dedicada y enviada por el propio Manuel de Falla a Gerardo Diego una vez comenzado el curso soriano $^{37}$, reflejan no solo el conocimiento e interés que mostraba Diego por la música española de su tiempo, sino también las incipientes redes de contactos que comenzó a fraguar impulsado por sus anhelos de juventud de llegar a ser compositor. Unos anhelos frustrados de los que dejó testimonio poético en las Canciones a Violante de 1959: "Y quisiera ser músico, / músico de verdad, no de los pobres / que ajenas pautas suenan como propias, / equilibrista por los cinco alambres / con riesgo a cada pájaro / de romperse la crisma" 38 .

A grandes rasgos, según anunció la prensa local en febrero de 1921 y tal y como reseñó Salazar en El Sol en septiembre de $1921^{39}$, Gerardo Diego organizó su "Historia de la música para piano" de la siguiente manera: una primera época dedicada a "los clavecinistas italianos, alemanes y franceses"

35 Ad. S., "La vida musical. Algunas nuevas obras españolas. Un curso de historia de la música para piano", El Sol, Madrid, 4-9-1921, p. 3.

${ }^{36}$ La obra de Malipiero fue incluida en Le tombeau de Claude Debussy, una obra colectiva comisionada por Henri Prunières, director de la Revue Musicale, que incluía diez composiciones firmadas por los compositores más reconocidos del momento: Paul Dukas -bajo el título La plainte, au loin, du faune y también interpretada por Diego en Soria-, Albert Roussel, Gian Francesco Malipiero, Eugène Goossens, Béla Bartók, Florent Schmitt, Manuel de Falla, Maurice Ravel, Erik Satie e Igor Stravinsky. La Biblioteca de Gerardo Diego conserva un ejemplar de este número publicado en diciembre de 1920. Véase Bliblioteca de Gerardo Diego. Catálogos: Música I, Santander, Fundación Gerardo Diego, 2008, p. 148

${ }^{37}$ Carta de Gerardo Diego a Manuel de Falla, Soria, 12-2-1921 y carta de Manuel de Falla a Gerardo Diego, Granada, 3-3-1921. F. Sopeña (ed.): Gerardo Diego-Manuel de Falla..., pp. 12 y 17. Gerardo Diego recordó seis décadas después haber visto esta partitura en casa del pianista Gabriel Abreu y el hecho de que Falla le envió una copia dedicada de la edición de la "Danza ritual del fuego" realizada por la editorial Renacimiento; Gerardo Diego: "La memoria intermitente", ABC, Madrid, 24-1-1980, p. 1.

${ }^{38}$ G. Diego: "Y quisiera ser músico", Canciones a Violante (1959), Gerardo Diego. Poesía completa I, F. J. Díez de Revenga (ed.), Valencia-Santander, Editorial Pre-Textos-Fundación Gerardo Diego, 2017, p. 882 .

${ }^{39}$ A. S.: "La vida musical. Algunas nuevas obras españolas. Un curso de historia de la música para piano", El Sol, Madrid, 4-9-1921, p. 3. 
y que le ocupó las tres primeras sesiones; una segunda centrada en "la sonata clásica", objeto de la cuarta y quinta sesión; una tercera época dedicada a "los románticos" y que ocupó las sesiones sexta, séptima y octava y una cuarta época centrada en "la música moderna" y repartida en las tres siguientes sesiones dedicadas, respectivamente, al nacionalismo, Claude Debussy y la música contemporánea. Finalmente, las dos últimas sesiones fueron dedicadas a la música española abordando, en sus intervenciones, el repertorio de los "viejos maestros (organistas, vihuelistas y clavecinistas)" 40 e interpretando desde la Suite española de Isaac Albéniz al Falla más contemporáneo. En resumen, dos siglos de literatura pianística, cuarenta y dos compositores y más de setenta obras fueron interpretados, un hito fundamental en una pequeña ciudad provinciana cuyo repertorio pianístico habitual hacia 1920 no iba más allá de Beethoven, Chopin, Wagner, Grieg o Liszt, tal y como Palacios Sanz y Martín de la Guardia han concluido recientemente ${ }^{41}$.

\section{Gerardo Diego y la literatura pianística de todos los tiempos}

Ante tamaña propuesta musical, llevada a cabo por un músico no dedicado profesionalmente a la interpretación pianística, cabe preguntarse cuál era el bagaje musical y cultural con el que Gerardo Diego contaba para abordar un programa de tales dimensiones como conferenciante e intérprete. La reciente publicación de Ramón Sánchez Ochoa hace hincapié en la vasta cultura musical que Diego atesoró a lo largo de su vida. Queda atestiguada en su amplia biblioteca musical, de la que hoy se conservan más de 580 títulos en la Fundación Gerardo Diego de Santander ${ }^{42}$, y alrededor de 1300 títulos de partituras en su mayoría dedicadas al repertorio desde el siglo XVIII al XX para piano solo ${ }^{43}$, hoy custodiadas por sus hijas Isabel y Elena Diego en Madrid.

Una afición por la música en general y el piano en particular que perduró toda su vida y que, como apuntó Ana Benavides, permeó en su producción literaria y ensayística ${ }^{44}$. Durante su adolescencia santanderina, Diego prosiguió una formación autodidacta centrada en el piano en la que el Gradus ad Parnassum de Muzio Clementi cimentó la técnica con la que enfrentarse, según Sánchez Ochoa, a las "numerosas sonatinas de Domenico Scarlatti, por las que sentirá siempre particular debilidad, algunas páginas de

\footnotetext{
40 "Ateneo de Soria. Curso de historia de la música de piano", AvN, Soria, 28-5-1921, p. 2.

${ }^{41}$ J. I. Palacios Sanz, R. Martín de la Guardia: "Casinos y espacios de recreo...”, p. 337.

${ }^{42}$ R. Sánchez Ochoa: Poesía de lo imposible..., p. 32. Véase Bliblioteca de Gerardo Diego. Catálogos: Música I.

${ }^{43}$ R. Sánchez Ochoa: Poesía de lo imposible..., p. 33. La relación del inventario provisional aparece en A. Benavides: Gerardo Diego y la música..., pp. 271-310.

44 A. Benavides: Gerardo Diego y la música..., pp. 29-180.
} 
Mozart y Beethoven, y solo contadas piezas de Johann Sebastian Bach"45. Si Scarlatti, Mozart y Beethoven fueron sus primeros compañeros de viaje, pronto tornó su interés hacia los compositores románticos, entre los que Chopin encuentra un lugar predilecto al lado de Mendelssohn, Schubert y Schumann, y hacia Claude Debussy, al que descubrió a través de un concierto ofrecido por Emil Sauer en Santander ${ }^{46}$.Ya antes de 1920, dedicó a todos ellos sus poemas de juventud Medallones Románticos, que acompañaron la interpretación de sus obras ante el público soriano ${ }^{47}$. Pero, además, su paso por Bilbao y Madrid durante la segunda década del siglo XX le permitió entrar en contacto con los miembros más prominentes de la vanguardia musical española y europea. A Bilbao llegó en 1912 para cursar estudios de Filosofia y Letras en la Universidad de Deusto. Una ciudad que, según sus propias palabras,

se iba a convertir insensiblemente en la capital de mi corazón. Poder mágico de la adolescencia, de la ilusión juvenil, de la vocación artística -poesía y música[...] y del amor. Tuve además la suerte de encontrar en Bilbao buenísimos amigos y uno de ellos, Juan Larrea, se convertiría año tras año en mi mentor más lúcido, cariñoso y entusiasta [...].Y las primeras representaciones de ópera en el Arriaga. Y los conciertos de la Filarmónica.Y mi descubrimiento y lecturas a dos, mis dos, o cuatro manos con las del cultísimo Sautu, mi mentor en la nueva música: César Franck, Debussy, Guridi, que había estrenado Mirentxu y empezaba a trabajar en Amaya. Mi primer concierto en la S. Coral y mi nombre en los periódicos en letras de molde y augurios de porvenir.Y, no hay que olvidarlo, el toreo, mi tercera arte junto a la poesía y la música ${ }^{48}$.

Su primer concierto público lo ofreció, junto al violinista Jesús Estefanía, durante el curso 1915-16 en la Sociedad Coral de Bilbao interpretando la Sonata para violín y piano, op. 24 "Primavera" de Beethoven. Con Juan Larrea compartió, entre otras, la pasión por el repertorio wagneriano llegando a dedicarle, años más tarde, su poema San Juan. Poema sinfónico en el modo wagneriano ${ }^{49}$. Diego residió en Bilbao durante los años centrales de la década de 1910, en la que las prácticas asociativas impulsadas a finales del

\footnotetext{
${ }^{45}$ R. Sánchez Ochoa: Poesía de lo imposible..., p. 20.

46 Ibid., p. 79.

47 Gerardo Diego escribió en 1918 sus Medallones románticos dedicados a Schubert, Mendelssohn y Schumann. Cuando preparó la edición completa de su obra en 1985 agrupó estas obras hasta entonces inéditas bajo el epígrafe Hojas; F. J. Díez de Revenga (ed.): Gerardo Diego. Poesía completa II..., pp. 1043-1045. El soneto dedicado a Mendelssohn apareció publicado, en una versión anterior, con motivo de la reseña de su sexta conferencia-concierto en Soria. "Ateneo de Soria. Historia de la música de piano", AvN, Soria, 20-4-1921, p. 2. No hay constancia, sin embargo, de que recitase D’après Debussy en sus conferencias sorianas.

48 G. Diego: "Deusto 1959" [Inédito. Abril 1959], Díez de Revenga: Gerardo Diego. Obras completas. Tomo IV..., pp. 184-191; 189

${ }^{49}$ R. Sánchez Ochoa: Poesía de lo imposible..., pp. 20-21.
} 
siglo XIX se consolidaron gracias a la prosperidad económica de la burguesía industrial que demandaba una intensa actividad artística y promocionó la creación de una ópera vasca, como ha apuntado María Nagore ${ }^{50}$. El ambiente musical del Bilbao de aquella época era solo comparable en España al de núcleos urbanos como Madrid y Barcelona y, en este contexto, Diego entró en contacto con la obra de José María Usandizaga, con el más temprano Padre Donostia y con el compositor francés Cesar Franck, definido en su octava conferencia como "el último representante de los viejos colosos de la música" 51 . La Sociedad Coral de Bilbao estaba entonces liderada por Jesús Guiridi quien, junto a Usandizaga, lideró el movimiento de creación de la ópera vasca inspirada en el folklore y sustentada por el lenguaje tardo-romántico. Además, continuó con el cultivo del gran repertorio sinfónico-coral al abrigo de la Sociedad. Años más tarde, Diego interpretó ante el público soriano, y en su propio arreglo pianístico, el preludio y la romería de la "pastoral lírica vasca en tres actos y epílogo" Mendi-Mendiyan que, a su juicio, era la mejor obra de Usandizaga, de quien también interpretó la inédita En la aldea están de fiesta ${ }^{52}$.

Tras Bilbao, llegó el turno de Madrid, donde se licenció por la Universidad Central en verano de 1916 y donde residió hasta mayo de 1917.Tras pasar el verano y otoño de 1917 en Santander, Gerardo Diego regresó a Madrid en marzo de 1918 con el sueño de ser compositor a la vez que cursaba su doctorado en Filosofia y Letras y aprovechaba la oferta cultural que la ciudad le ofrecía ${ }^{53}$. En la capital asistió a los conciertos semanales de la Orquesta Filarmónica en el Teatro-Circo de Price y a las representaciones de los Ballets Rusos, con tan solo diecinueve años, en mayo de 1916 en el Teatro Real. Una experiencia en la que, de acuerdo con sus propias palabras, "uno no sabía si taparse los oídos para ver mejor o cerrar los ojos para

50 María Nagore Ferrer: "La realidad musical vasca en el periodo de entreguerras", Música española entre dos guerras, 1914-1945, Javier Suárez Pajares (ed.), Granada, Ayuntamiento de Granada-Publicaciones del Archivo Manuel de Falla, 2002, pp. 133-163; 138-151. Véase también Ramón Rodamilàns: La Sociedad Filarmónica de Bilbao, 2 vols., Bilbao, Sociedad Filarmónica de Bilbao-BBK, 1999.

51 "Ateneo de Soria. Historia de la música de piano", AvN, Soria, 30-4-1921, p. 2.

52 La biblioteca musical de Gerardo Diego conserva una copia de En la aldea están de fiesta. Véase A. Benavides. Gerardo Diego y la música..., p. 308. El manuscrito de esta obra puede ser consultado en la web del Fondo J. M. Usandizaga perteneciente al Eresbil (Archivo Vasco de la Música), (http://www.eresbil.com/web/usandizaga/presentacion.aspx?lang=es, consulta 8-6-2018).

53 Para un breve contexto véase Emilio Casares Rodicio: "La Sociedad Nacional de Música y el asociacionismo musical español", Cuadernos de Música Iberoamericana, 8-9, 2001, pp. 313-322; Ramón Sobrino: "Paisaje musical de Madrid en el primer tercio del siglo XX: las instituciones orquestales y la Banda Municipal de Madrid", Recerca Musicològica, XIV-XV, 2004-05, pp. 155-175; Miriam Ballesteros Egea: "La Orquesta Filarmónica de Madrid (1915-1945) y su contribución a la renovación musical española", tesis Doctoral, Universidad Complutense de Madrid, 2010 (http://eprints.ucm.es/11071/1/ T32198.pdf) y José María García Laborda: La Sociedad Filarmónica de Madrid (1901-1936). Contexto histórico y valoración de repertorio, Vigo, Editorial Academia del Hispanismo, 2011. 
poder gozar una música excesiva" 54 . Tuvo también la oportunidad de escuchar al pianista Arthur Rubinstein, a quien la crítica madrileña consideró "verdadero intérprete de Chopin" 55 y de quien Diego escuchó por primera vez la música de Scriabin durante su gira española de 1916-1917. Es probable que asistiese al recital de despedida celebrado el 20 de enero de 1917 en el Teatro Lara con un programa dedicado íntegramente a Chopin y en el que Rubinstein interpretó las “obras zurdas" -Preludio y Nocturno, Op. 9- de Scriabin como propina ${ }^{56}$. En Soria, Diego presentó a Scriabin como un músico que "de ser un imitador elegante de Chopin pasó a representar uno de los aspectos más audaces del arte contemporáneo con sus últimas obras de técnica novísima y de carácter atormentado y místico" e ilustró dicha evolución con una selección de preludios scriabinianos ${ }^{57}$, compuestos entre 1888 y 1914. La obra de Scriabin causó una impresión duradera en el universo musical de Diego, llegando a afirmar que "tres han sido los verdaderos inventores del piano. El primero se llamó Federico Chopin. El segundo y el tercero, al mismo tiempo y por distintos caminos y con diversos resultados, Claudio Debussy y Alejandro Scriabin"58.

El 27 de abril de 1918, Diego presenció en el Ateneo de Madrid la velada en homenaje a Claude Debussy y en 1980 la recordaba con las siguientes palabras:

En marzo de 1918 muere Claude Debussy. Si me acuerdo de esta tristísima fecha es porque dio ocasión a que yo viera y escuchara a Manuel de Falla; mas no tocando el piano, sino hablando, leyendo una breve disertación:"El arte profundo de Claude Debussy". La conmemoración del mágico se efectuó en el Ateneo de Madrid. Guardo -tan bien que, de momento no lo puedo encontrar- el programa. Tocó Arturo Rubinstein una magnífica y amplia antología de la obra debussyana, ya solo o acompañado al canto.Y hubo además la presencia y la emocionada palabra de Falla ${ }^{59}$.

Las palabras de Falla, conocedor de primera mano de la música y personalidad del compositor francés, influenciaron las palabras que Gerardo

${ }^{54}$ G. Diego: "Programa 'Stravinsky" [Original inédito, Radio Nacional de España, febrero 1946], Gerardo Diego. Prosa musical I. Historia y crítica musical, R. Sánchez Ochoa, Elena Diego Marin (eds.), Valencia-Santander, Editorial Pre-Textos-Fundación Gerardo Diego, 2014, p. 305

${ }^{55}$ R. de C.: "Conciertos Rubinstein", La Correspondencia de España, Madrid, 13-2-1917, p. 7.

56 A. B.: "Teatro Lara. Último concierto Rubinstein", La Época, Madrid, 21-1-1917, p. 3. Gerardo Diego recordaba, años más tarde, haber escuchado a Arthur Rubinstein interpretar algunas obras de Scriabin antes de 1921. Véase Gerardo Diego: "Vigencia de Scriabin", Arriba, Madrid, 28-1-1973. Gerardo Diego. Prosa Musical I..., p. 187.

57 "Ateneo de Soria. Historia de la música de piano", AvN, Soria, 7-5-1921, p. 2

${ }^{58}$ G. Diego: "Expresión y formas de la música a través de sus grandes maestros Scriabin-StravinskyProkofiev". [Original Radio Nacional de España, s. f.], Gerardo Diego. Prosa Musical I..., p. 314.

${ }^{59}$ G. Diego: "La memoria intermitente", ABC, Madrid, 24-1-1980, p. 3. En el Homenaje a Debussy participaron Manuel de Falla como ponente, Arthur Rubinstein al piano, la soprano Aga Lahowska y la Orquesta Filarmónica de Madrid dirigida por Bartolomé Pérez Casas. "En el Ateneo. Homenaje a Debussy", La Época, Madrid, 28-4-1918, p. 2 
Diego pronunció en Soria sobre "la más alta gloria de la música moderna", tal y como la prensa local definió a Debussy ${ }^{60}$. Diego comentó el temperamento "sutilmente poético" de las colecciones pianísticas Images, Estampes y Préludes, que enriquecieron "la técnica del instrumento con sonoridades completamente nuevas e inesperadas" 61 . La obra de Debussy originó, según Falla, "una transformación profunda y definitiva del arte sonoro" 62 y acercó a Diego, más que a ningún otro compositor, "a la equivalencia poética en palabras de una música que es ya, ella misma, espiritual y materialmente, poesía en sonidos"63 , tal y como apuntó en 1941 en las "Notas" a su Alondra de verdad. Para un poeta creacionista como él, Debussy convirtió las teclas del piano en expresivas letras que evocan "Sonidos y perfumes [...] / Iberia, Andalucía, España en sueños, / lentas Granadas, frágiles Sevillas, / Giraldas tres por ocho, altas Comares [...]"64.

Fue asimismo en Madrid donde Gerardo Diego conoció de primera mano la música de Falla, Turina y otros contemporáneos y donde inició su amistad con Federico García Lorca en el contexto del Ateneo o de la Residencia de Estudiantes durante el curso 1919-20, como el propio músicopoeta recordaba años más tarde ${ }^{65}$. En Madrid también asistió a los conciertos organizados por la recién fundada Sociedad Nacional de Música, que hizo de la defensa de los músicos españoles contemporáneos y de las nuevas corrientes europeas su sello de identidad ${ }^{66}$, y entabló amistad con su secretario, el musicólogo, compositor y crítico Adolfo Salazar. En este contexto, y en clara sintonía con Salazar, Diego asumió los paradigmas de modernidad que se inclinaban hacia el impresionismo francés y la obra de herencia nacionalista de los rusos del Grupo de los Cinco sin olvidar al más reciente Stravinsky ${ }^{67}$. Asimismo, asistió a los conciertos históricos

\footnotetext{
60 "Ateneo de Soria. Historia de la música de piano". AvN, Soria, 7-5-1921, p. 2.

${ }^{61}$ Ibid. AvN, Soria, 18-5-1921, p. 2.

${ }^{62}$ Manuel de Falla: "El arte profundo de Claude Debussy", citado en Yvan Nommick: "Debussy y Falla. Un encuentro decisivo en París", La Opinión de Granada, 29-1-2006.

${ }^{63}$ G. Diego: "Notas a 'A C. A. Debussy", Alondra de Verdad (1941), Gerardo Diego. Obras comple-
} tas. Tomo I. Poesía, F. J. Díez de Revenga (eds.), Madrid, Aguilar, 1989, pp. 505-506.

${ }^{64}$ G. Diego: "A C. A. Debussy", Alondra de Verdad (1941), Gerardo Diego. Obras completas. Tomo I..., p. 477.

65 "Pues bien; si ahora paso a evocar mi conocimiento de Federico García Lorca he de remontarme a 1919 muy probablemente o, en todo caso, a 1920. Mi memoria vacilante no puede precisar lugar y momento. ¿El Ateneo? ¿La Residencia de Estudiantes? Lo seguro es que para la segunda de estas fechas ya éramos amigos instantáneos". Gerardo Diego: "La memoria intermitente", ABC, Madrid, 24-1-1980, p. 3.

${ }^{66}$ Para una idea general de su programación véase David Ferreiro Carballo: "La Sociedad Nacional de Música (1915-1922) y su papel en la introducción de las nuevas corrientes musicales en España", Actas del Congreso Internacional "El amor brujo, metáfora de la modernidad (1915-1916)". Estudios en torno a Manuel de Falla y la música española del siglo XX, Elena Torres Clemente, Francisco J. Giménez Rodríguez, Cristina Aguilar Hernández, Dácil González Mesa (eds.), Madrid-Granada, Centro de Documentación de Música y Danza-INAEM-Fundación Archivo Manuel de Falla, 2017, pp. 799-830.

${ }^{67} \mathrm{Al}$ respecto de la modernidad musical asumida por Adolfo Salazar, véase Consuelo Carredano: "Adolfo Salazar en España. Primeras incursiones en la crítica musical: la Revista Musical Hispano-Americana (1914-1918)", Anales del Insitituto de Investigaciones Estéticas, 84, 2004, pp. 119-144; 128. 
ofrecidos por Joaquín Nin en el Hotel Ritz en mayo de 1917 y $1918^{68}$, "cuando el artista contaría algunos años más de los que representaba, siempre pulquérrimo y sonriente bajo su abundante cabellera ondulada y rubia, con reminiscencias de peluca dieciochesca", tal y como Diego recordaba ${ }^{69}$. La asistencia a estos conciertos influenció los programas de sus tres primeras conferencias-concierto sorianas. En la primera, impartida el 15 de febrero, Diego habló de los "clavecinistas italianos, alemanes y franceses" y explicó, tal y como recogieron las páginas de El Avisador Numantino, todos los instrumentos de teclado predecesores del primitivo fortepiano inventado por Bartolomeo Cristofori en los albores del siglo XVIII, desde

el clavicordio que hiere las cuerdas por una lengüeta metálica que forma cuerpo con el teclado, y el clave címbalo que las ataca por medio de púas, también unidas a las teclas. En ambos instrumentos desarrollaron sus ingenuas melodías los músicos del renacimiento, los inspirados clavecinistas de los siglos XVI y XVII, hasta que en 1711 el nuevo ensayo de sustituir la lengüeta y las púas por mazillos [sic] y el empleo de los pedales asegura el porvenir de la música de cuerda con el éxito del instrumento que los italianos denominaron piano forte ${ }^{70}$.

Frescobaldi, Rossi y Scarlatti y su Sonata en Sol menor K30 abrieron el programa representando a los clavecinistas italianos. Pero Scarlatti lo hacía como "inmenso virtuoso, casi español" 71 , dado que fue en España donde compuso casi la totalidad de sus sonatas para teclado. Pero, además, el hecho de que Diego centrase el repertorio clavecinístico en las escuelas italiana -que "por su tradición artística popular y por espíritu de raza" son "maestros en la suite, composición armónica y alegre"-, alemana -que "con el peso tradicional de la música litúrgica, descuellan en la fuga, composición más solemne"- y francesa, "hermanos de los italianos y como ellos ligeros y expresivos"72, sitúan a Diego como conocedor de las conferencias-concierto impartidas por Joaquín Nin en la Sociedad Filarmónica de Bilbao en enero de $1913^{73}$, cuando ya estudiaba en Deusto.

\footnotetext{
${ }^{68}$ Programas de mano: Concierto 34 de la Sociedad Nacional de Música, Madrid. Año III 1916-1917. Concierto XIII. El miércoles 23 de mayo. Primer concierto de obras para piano por J. Joaquín Nin. Granada, Archivo Manuel de Falla, NFN 1917-004 y Concierto 47 de la Sociedad Nacional de Música, Madrid. Año IV 1917-1918. Concierto XII. El martes 21 de mayo. Música del siglo XVIII para clave por J. Joaquín Nin. Granada, Archivo Manuel de Falla, NFN 1918-009.

${ }_{69}$ G. Diego: "Pianistas", Escorial, XXI, 1950, Gerardo Diego. Prosa Musical I..., p. 766.

70 "Cursos del Ateneo", AvN, Soria, 19-2-1921, p. 2.

${ }^{71} \mathrm{Ibid}$. En las notas al programa del concierto ofrecido por Jaoquín Nin el 23 de mayo de 1917 en el Hotel Ritz se apuntaba la scarlattiana síntesis de "la exuberancia, la sensualidad y la vivacidad napolitanas con la elegancia, la energía, la expresividad y el sentido de lo pintoresco propios de España". Véase Salazar, Ad. Notas al programa. Concierto 34 de la Sociedad Nacional de Música, p. 7. Granada, AMF, NFN 1917-004.

72 "Cursos del Ateneo", AvN, Soria, 19-2-1921, p. 2.

${ }^{73}$ Joaquín Nin: Las tres grandes escuelas musicales del siglo XVIII: conferencias pronunciadas por Joaquín Nin en la Sociedad Filarmónica de Bilbao, Bilbao, Sabino Ruiz Edit., 1913.
} 
A pesar de que el repertorio escogido para la primera sesión no está detallado en las reseñas de la prensa local ${ }^{74}$, podemos suponer que interpretó una selección de piezas contenidas en las antologías Alte Meister, editada por Breikopft \& Härtel en cuatro volúmenes, y Clavecinistes Français, publicada por Durand en París, que hoy se conservan en su biblioteca ${ }^{75}$. Por otro lado, la familiaridad de Gerardo Diego con la música del siglo XVIII y con los instrumentos predecesores del piano queda ilustrada con las "más poéticas que pedagógicas palabras" que abren el Preludio escrito en 1918 y publicado en 1963 como antesala a los Nocturnos de Chopin:

El piano sueña. Sueña en la estela, tierna y abuela, del clavicordio con la vihuela, con el laúd.

El piano sueña. Sueña en el eco

frágil y seco

del clavicémbalo con la flauta llena de luz.

Gavota y Doble [obra de Rameau interpretada en la segunda sesión], Giga, Alemanda

y Zarabanda

rizan floreos: Bach, Scarlatti, Haendel, Rameau.

Y van los dedos pespunteando,

tricoteando,

-duras delicias trinos-, mordientes de ágil rondón ${ }^{76}$.

A continuación, Diego ilustró "el contraste entre la música de los clavecinistas y la de los primeros ensayos de la música de piano", unas diferencias que Diego achacó a las "poderosas influencias de la nacionalidad, de la época y aún de la religión, y por de contado, por la evolución natural estética y técnica que la música había de tener al valerse de un nuevo instrumento, el piano", como recogió el Avisador Numantino ${ }^{77}$. Centró las cuarta y quinta conferencias en la sonata clásica, en la que "el piano sueña. Sueña en el timbre / que tiemble y cimbre, / toda su plata, todo su oro, su iris vienés", tal y como Diego sintetizó en su Preludio ${ }^{78}$, interpretando obras de Mozart y Beethoven. De este último, Diego destacó su terrible sordera, su temperamento apasionado y la influencia que ejerció en todo el siglo XIX, sintetizando su

\footnotetext{
${ }^{74}$ Además, gran parte de los nombres de compositores aparecen con considerables errores tipográficos, lo que presupone un desconocimiento del repertorio interpretado por parte del cronista. Véase "Ateneo de Soria. Historia de la música de piano", AvN, Soria, 19-2-1921, p. 2 y "Ateneo de Soria. Historia de la música de piano", NoS, Soria, 18-2-1921, p. 2.

75 A. Benavides: Gerardo Diego y la música..., p. 309

${ }^{76}$ G. Diego: Nocturnos de Chopin..., p. 29.

77 "Ateneo de Soria. Historia de la música de piano", AvN, Soria, 9-3-1921, p. 2.

${ }^{78}$ G. Diego: Nocturnos de Chopin..., p. 29
} 
obra según los tres estilos o maneras que Wilhelm von Lenz popularizó a partir de 1852 e interpretando, para ilustrar cada uno de ellos, las Sonatas n. ${ }^{\circ}$ 8 Patética, $n{ }^{\circ} 23$ Appassionata y n. ${ }^{\circ} 31$ respectivamente. La prensa local alabó que Diego superase "las excelencias a que nos tenía acostumbrados, revelándose como un gran virtuoso y como un admirable intérprete de Beethoven"'79. Su Preludio a los Nocturnos de Chopin continúa:

Y el piano sueña pálida musa.

De blanca a fusa,

romanticismos que le agitaron el corazón.

Todas sus cuerdas se estremecieron,

todas sufrieron,

nervios vibrantes, los huracanes de la emoción.

Sueña las manos blancas, sutiles,

manos febriles,

sus diez alfiles largos, ardientes de infinitud.

Con qué dulzura tierna flotaban

y acariciaban

en la piel fría-dominó raso-su tornaluz ${ }^{80}$.

Con estos versos Diego evoca la personalidad de su compositor predilecto, al que dedicó la conferencia central de su "Historia de la música para piano" el día 16 de abril, tras el parón de Pascua. De Chopin, el Diego poeta destacó "su temperamento enfermizo y sensitivo, y de nativa elegancia de espíritu". Mientras, el Diego pianista destacó su novedosa técnica, "pues a la vez que es poeta del piano, evocador de todas las emociones decadentes y crepusculares, [Chopin] es también un precursor de los modernos en sus 'Mazurcas', 'Preludios' y 'Polonesas', tan sabrosas de ritmo y de color popular" 81 , apelando, sin duda, al hecho de haber sido el polaco uno de los primeros compositores en estilizar danzas y ritmos populares. Pero, para el conferenciante, Chopin era, ante todo y a juzgar por su emplazamiento central, el máximo representante del Romanticismo y la piedra angular de una época que fue también ilustrada, en una ponencia previa, con obras de Schubert, Weber y Mendelssohn y, en una posterior, con obras de Schumann, Liszt y César Franck, además de con la lectura de los Medallones románticos escritos en 1918.

${ }^{79}$ J. T.: "Ateneo de Soria. Historia de la música de piano", AvN, Soria, 16-3-1921, p. 2. En 1927, y para celebrar el centenario de la muerte de Beethoven, Diego ofreció en Gijón una conferencia-concierto de similares características en la que la única diferencia fue sustituir la Sonata Appasionata por la Sonata Claro de luna para ilustrar el segundo periodo.

${ }^{80}$ G. Diego: Nocturnos de Chopin..., p. 30.

81 "Ateneo de Soria. Historia de la música de piano", AvN, Soria, 20-4-1921, p. 2. 
De Schubert, "romántico sin saberlo" según la prensa local" presó en sus Medallones que "Mozart es su profeta y su pasión Beethoven" para acabar ensalzando su alma de poeta "y oír el Lied que fluye desde su corazón"83, presente en los Impromptus y Momentos Musicales, obras "libres y poéticas", decía el Avisador Numantino ${ }^{84}$, que Diego escogió como representativas de su producción. Con toda probabilidad, el Impromptu n. ${ }^{\circ} 3$ D 899 en Sol bemol mayor fue interpretado como anticipo a la selección de Canciones sin palabras de Mendelssohn con las que Diego concluyó la velada. Mendelssohn, "artista y mecenas" a quien Diego describió en 1918 como "la elegancia misma.Y a la vez un fanático / de Bach, el contrapunto, la fuga y el coral" ${ }^{85}$, representó en estas Canciones, con "caprichosa ligereza y morbosa melancolía" según la prensa local ${ }^{86}$, la quintaesencia artística del literato santanderino. Tanto de Schubert como de Mendelssohn, Diego escogió aquellas miniaturas pianísticas que imitaban el arte de la canción sin llegar a incluir texto alguno como obras ilustrativas de su creación musical. Un hecho representativo dado que, en 1962 , Gerardo Diego confesó que "yo soy poeta porque no puedo ser músico" si "hubiera aprendido el lenguaje de la composición musical y hubiera logrado crearme dentro de él mi metal de voz propio, todo lo que intento decir con la palabra lo hubiera confiado al sonido. La más pura inaccesible poesía empieza donde la palabra concluye y nace la música" 88 . Una afirmación en clara sintonía con la explicación que Mendelssohn ofreció a Marc-André Souchay acerca de sus Lieder ohne Worte. Tras afirmar que las palabras le parecen "tan ambiguas, tan vagas, tan fácilmente incomprendidas en comparación con la auténtica música", el compositor alemán afirma que "los pensamientos expresados a través de la música que me gusta no son demasiado imprecisos para ser puestos en palabras, más al contrario, demasiado precisos" 89.

\footnotetext{
82 "Ateneo de Soria. Historia de la Música para Piano", AvN, Soria 20-4-1921, p. 2.

${ }^{83}$ G. Diego: "Medallones románticos. Schubert" [Inédito, 1918]. Gerardo Diego. Poesía completa II..., pp. 1043-1044.

84 "Ateneo de Soria. Historia de la Música para Piano", AvN, Soria, 20-4-1921, p. 2.

${ }^{85}$ G. Diego: "Medallones Románticos. Mendelssohn" [Inédito, 1918]. Gerardo Diego. Poesía completa II..., p. 1044.

86 "Ateneo de Soria. Historia de la música de piano", AvN, Soria 20-4-1921, p. 2.

${ }^{87}$ G. Diego: "Música y ritmo en Gerardo Diego" [Original, conferencia, Ateneo de Madrid, abril de 1962], Gerardo Diego. Prosa Musical II. Pensamiento musical, R. Sánchez Ochoa, E. Diego Marin (eds.), Valencia-Santander, Editorial Pre-Textos-Fundación Gerardo Diego, 2015, p. 306.

${ }^{88}$ Gerardo Diego, Poeta mayor de Cantabria. Homenaje (1896-1996), Santander, Ayuntamiento de Santander, 1996, p. 123. Citado en A. Benavides: "Gerardo Diego. Un artista...", p. 97.

89 "These [words], too, seem to me so ambiguous, so vague, so easily misunderstood in comparison to genuine music, which fills the soul with a thousand things better than words. The thoughts which are expressed to me by music that I love are not too indefinite to be put into words, but on the contrary, too definite". Carta de Felix Mendelssohn-Bartholdy a Marc-André Souchay, Berlín, 15-101842, Gisella Selden Goth (ed.): Felix Mendelssohn. Letters, Londres, Paul Elek Publishers Ltd., 1946, pp. 313-314.
} 
Sobre Robert Schumann, Diego afirmó en el primer verso de su Medallón romántico que "es el puro romántico e invencible adalid"90. Sus obras para piano "reflejan maravillosamente el ambiente romántico de los años de 1830" en pequeños cuadros que evocan "escenas de niños, fantasías, evocaciones [y] arabescos, en que con plena libertad su visión poética de las cosas puede desarrollarse sin trabas", tal y como resumió la prensa local tras su conferencia ${ }^{91}$. No es por ello de extrañar que, en 1930, en las "Tres lecciones sobre Clasicismo, Romanticismo e Impresionismo" ofrecidas en el Ateneo Obrero de Gijón, Gerardo Diego situase a Schumann como representante del Romanticismo y ejecutase una selección de su obra desde los Papillons, op. 2 hasta los Albumblätter, op. 12492. En la conferencia soriana interpretó, sin embargo, la que consideraba su obra más representativa, el Carnaval, op. $9^{93}$, debidamente ilustrada en los siguientes versos de su Medallón: "Si Eusebius pierrotiza en el claro de luna, / Florestán acomete a la chusma inoportuna / ... y huyen los filisteos del arpa de David"94, evocando en este último verso a la última sección del Carnaval.

Antes de abordar los nacionalismos pianísticos, Diego concluyó su repaso por la literatura romántica para piano con Franz Liszt, "el más célebre virtuoso del piano". Si bien sus primeras obras "son solo fuegos artificiales, acumulación caprichosa y superficial de dificultades", los números de $A n$ nées de Pèlerinage que Diego eligió para ilustrar su conferencia recogen "las impresiones musicales de sus viajes artísticos, sus emociones personales ante paisajes, monumentos, cuadros, lecturas, con una fina sensibilidad y una amplitud y capacidad de apasionamiento enteramente modernas"95. En otras palabras, Années de Pèlerinage perfila al Liszt poeta del piano que compendia, con sus recursos estilísticos y técnicos, lo que un poeta podría evocar con palabras.

\footnotetext{
90 G. Diego: "Medallones Románticos. Schumann" [Inédito, 1918], Gerardo Diego. Poesía completa II..., p. 1045.

91 "Ateneo de Soria. Historia de la música de piano", AvN, Soria, 30-4-1921, p. 2.

92 Programa de mano. Tres lecciones sobre Clasicismo, Romanticismo e Impresionismo. Scarlatti, Schumann, Debussy. Por el catedrático del Instituto de Jovellanos D. Gerardo de Diego. Gijón, Ateneo Obrero de Gijón, 13, 14 y 15 de mayo de 1930. Granada, Archivo Manuel de Falla, NFN 1930-06. Diego interpretó una selección de diez sonatas de Scarlatti; Papillons, op. 2 y una selección de piezas extraídas de los Fantasiestücke, op. 12, Nachtstücke, op. 23, Album für die Jugend, op. 68, Albumblätter, op. 124, Waldszenen, op. 82 y Novelletten, op. 21 de Schumann; y una selección de Preludios de Debussy, el "Prélude" de la Suite Bergamasque, Soirée dans Grenade, Hommage à Ramaeu y Danses sacrée et profane.

93 "Ateneo de Soria. Historia de la música de piano", AvN, Soria, 30-4-1921, p. 2.

${ }^{94}$ G. Diego: "Medallones románticos, Schumann". [Inédito, 1918], Gerardo Diego. Poesía completa II..., p. 1045.

95 "Ateneo de Soria. Historia de la música de piano", AvN, Soria, 30-4-1921, p. 2.
} 


\section{Gerardo Diego y la modernidad}

La música interpretada hasta la octava conferencia-concierto refleja el bagaje adquirido por Gerardo Diego durante sus años de formación autodidacta y la profunda imbricación poético-musical que persistió a lo largo de su trayectoria vital. Sin embargo, el extraordinario conocimiento de la música de su tiempo que Diego adquirió durante sus años universitarios en Bilbao y Madrid quedó reflejado en los programas de las cinco últimas sesiones, programando obras compuestas, en su mayoría, en las dos primeras décadas del siglo XX. No cabe duda de que la relación de Gerardo Diego con Salazar y el contexto de la Sociedad Nacional de Música determinó y facilitó la inclusión de la obra de Dukas y Malipiero para el Tombeau de Debussy en la decimoprimera sesión y de la obra de Salazar y Falla en la última conferencia-concierto. Un hecho insólito para la Soria de la época y revolucionario en sí mismo si nos atenemos a novedad que representó entre el público madrileño la modernidad del repertorio presentado por la Sociedad Nacional de Música y que, por otro lado, pudo precipitar su desaparición según Ferreiro Carballo ${ }^{96}$.

Diego introdujo la sesión dedicada a los nacionalismos apuntando que, "a la vez que el Romanticismo producía sus últimos y más espléndidos frutos con los dramas líricos de Wagner, se ensayaban en países retirados de Europa (Bohemia, Noruega, Hungría, Rusia) nuevos procedimientos musicales, tomados directamente del acervo popular" ${ }^{97}$. Su selección de Danzas líricas de Edvard Grieg, compuestas entre 1867 y 1901, ilustraba la "elegancia de su escritura, defectuosa, pero espontánea y atrevida" y, sin duda, debió incluir en su elección alguna de las danzas del último libro para mostrar el lenguaje armónico avanzado del compositor noruego, de quien el público soriano había conocido, en 1918, la Suite Peer Gynt ${ }^{98}$. Pero fue la música de los compositores rusos la que ocupó la mayor parte de la conferencia, concluyendo la sesión con los Preludios de Scriabin, ya comentados, y presentando por primera vez ante el público soriano la "ingenua, bárbara y novísima” obra pianística de Modest Mussorgsky -los Cuadros de una exposición y el arreglo pianístico del Gopak- y la "fina, ponderada y polícroma" escritura pianística de Borodin, según la prensa local ${ }^{99}$.

\footnotetext{
${ }^{96} \mathrm{El}$ autor hace hincapié en la prevalencia de repertorio vanguardista y extranjero frente al de los compositores nacionales como posible causa de su desaparición. D. Ferreiro Carballo: "La Sociedad Nacional de Música...", p. 811.

97 "Ateneo de Soria. Historia de la música de piano", AvN, Soria, 7-5-1921, p. 2.

${ }^{98}$ El Ateneo de Soria organizó, en el Teatro Principal, el 21 de diciembre de 1918, la conferencia pública "El teatro de Ibsen y la música de Grieg". Véase J. A. Gómez Barrera. El Ateneo de Soria..., pp. 81 y 84.

99 "Ateneo de Soria. Historia de la música de piano", AvN, Soria, 7-5-1921, p. 2.
} 
Tras mostrar la modernidad musical de Debussy, cuya importancia radica, según Diego, en haber levantando "el nivel a un grado tal vez nunca alcanzado de pureza e idealidad musical" 100 , Gerardo Diego dedicó su antepenúltima conferencia-concierto a quienes él consideraba "evangelistas de la música nueva": Ravel, Stranvinsky, Bartók -no interpretado en Soriay Falla -trasladado a la sesión final-101, mostrando a los ateneístas sorianos lo más destacado de la vanguardia europea. Con el Ragtime de Stravinsky, "el más audaz de los maestros de hoy" según recogió el Avisador Numantino ${ }^{102}$, Diego introdujo por primera vez la nota americana y jazzística en el Salón del Casino de la capital soriana. Aunque esta obra compuesta en 1918 no es la más representativa del compositor ruso, destaca sin embargo por su fuerza rítmica, el tratamiento avanzado de una armonía dura y disonante y refleja su camaleónica y versátil personalidad. Las obras de Malipiero y Paul Dukas fueron publicadas en diciembre de 1920 -apenas cinco meses antes de su presentación en Soria- y el Kaleidoscope del anglo-belga Eugene Goossens fue compuesto en 1917 y publicado en 1918. Las humorísticas Descriptions automatiques de Erik Satie -tres breves piezas escritas en 1913 que parodian diferentes fragmentos de la música popular, desde el ritmo de tango a las marchas militares- "fueron muy comentadas por el auditorio regocijado", relataba la prensa local ${ }^{103}$. En gran medida, debido a las jocosas acotaciones literarias que adivinan la relación con el universo dadaísta que Satie experimentó apenas unos años más adelante. Pero el compositor estrella de esta antepenúltima sesión fue Maurice Ravel, "el más admirado de los músicos de hoy [...], a la vez muy clásico y muy moderno"104. Según Diego, es "clasicista más que clásico" 105 en las formas de su Pavana, Sonatina y en Le tombeau de Couperin, de la que interpretó el Rigaudon. Aunque también "busca para su inspiración motivos poéticos y libres", puntualizó Diego en su conferencia ${ }^{106}$, como en "El valle de las campanas" de Miroirs, obra que Diego continuó presentando fragmentariamente en posteriores ponencias ${ }^{107}$.

${ }^{100}$ G. Diego: "En torno a Debussy", Revista de Occidente, 42, diciembre 1926, Gerardo Diego. Prosa musical I..., p. 255. Diego publicó este artículo para rebatir la tesis de su coetáneo César M. Arconada, quien publicó en 1926 En torno a Debussy situando al compositor francés como colofón de la era romántica.

${ }^{101}$ G. Diego: "Béla Bartók, en España (para las Filarmónicas asturianas)", El Noroeste, 16-3-1927, Gerardo Diego. Prosa Musical I..., p. 299.

102 "Ateneo de Soria. Historia de la música de piano". AvN, Soria, 18-5-1921, p. 2.

${ }^{103}$ Ibid.

${ }^{104}$ Ibid.

105 G. Diego: "Ravel, Rabel y el rabelín", Revista de Occidente, 13-7-1924, Gerardo Diego. Prosa Musical I..., p. 265

106 "Ateneo de Soria. Historia de la música de piano", AvN, Soria, 18-5-1921, p. 2.

107 Gerardo Diego recordaba años más tarde que fue, precisamente Miroirs, la obra que Ravel le dedicó en 1928 tras un concierto en la Filarmónica de Oviedo: "A Gerardo Diego, Maurice Ravel". Gerardo Diego: "Ravel en Oviedo", Arriba, 9-3-1975, Gerardo Diego. Obras completas. Tomo IV..., pp. 449-451. 
El cronista del Avisador Numantino no pudo, por tanto, estar más acertado al juzgar a Diego como "uno de los más valiosos representantes" del grupo avanzado de la poesía española contemporánea que "no podía por menos de seguir análogas tendencias y orientaciones en sus aficiones musicales, mostrando su entusiasmo y sus fervores por los músicos más progresivos de estos últimos años" ${ }^{108}$. Una admiración por la música de su tiempo que tuvo como colofón las dos sesiones finales dedicadas a la música española. La primera tuvo como objeto a los compositores españoles fallecidos. Diego esbozó un breve resumen de la historia de la música española ensalzando la labor de los "organistas, vihuelistas y clavecinistas españoles", aunque no interpretó ningún ejemplo, y valoró la labor "humilde y constante de folkloristas y musicólogos tan eminentes como el P. Olmeda [...] y Felipe Pedrell, maestro de toda la actual generación" 109 . Si bien la interpretación de "Castilla" de la Suite española relacionaba a Isaac Albéniz con el influjo pedrelliano en cuanto a la recuperación del folklore para crear música española, Diego destacó la segunda época del compositor, convertido en "el patriarca de la música moderna española con la 'Suite Iberia', maravillosa colección de soberbios poemas nacionales, en que los ritmos y los cantos de la raza se cubren de las más suntuosas vestiduras en un magnífico alarde de color y de luz y de virtuosismo pianístico"110. La prensa destacó el numeroso público que asistió a esta penúltima sesión, sin duda atraído por la novedad que suponía la música española para piano, que no formó parte del repertorio habitual de la capital soriana hasta los años treinta ${ }^{111}$. La velada concluyó con la interpretación de "El fandango del candil" de las Goyescas de Enrique Granados, "más lírico, voluptuoso y elegante" que Albéniz a juicio del conferenciante, y con las citadas obras de Usandizaga.

A las siete de la tarde del lunes 30 de mayo de 1921 comenzó la segunda sesión y última del ciclo, centrada en los músicos españoles contemporáneos "con valor propio dentro de la música moderna universal" entre los que Diego contaba con no pocos amigos y siendo Manuel de Falla su protagonista indiscutible. Abrió la primera parte con Joaquín Turina, descrito como "uno de nuestros jóvenes maestros más cultos y laboriosos"112. Interpretó su Sonata romántica, una de las pocas piezas que finalizó en París, en 1909, y que a modo de tombeau plagado de giros folklóricos honra la memoria del fallecido Albéniz, maestro de maestros de la escuela española. Salazar, más conocido por su producción crítica que compositiva, fue descrito en la reseña publicada en el Avisador Numantino como "cultísimo musicólogo y crítico, al cual se debe en

\footnotetext{
108 "Ateneo de Soria. Historia de la música de piano", AvN, Soria, 18-5-1921, p. 2.

109 "Ateneo de Soria. Curso de historia de la música de piano", AvN, Soria, 28-5-1921, p. 2.

110 Ibid.

${ }^{111}$ J. I. Palacios Sanz, R. Martín de la Guardia: "Casinos y espacios de recreo...", p. 337.

112 "Ateneo de Soria. Historia de la música de piano", AvN, Soria, 8-6-1921, p. 2.
} 
gran parte la orientación de nuestros conciertos y sociedades musicales hacia una modernidad inteligente y progresiva" -apelando, sin duda, a su labor en la Sociedad Nacional de Música y sus colaboraciones con la Revista Musical Hispanoamericana y periódico El Sol- y cuyos ensayos de composición, en este caso los Tres preludios, le muestran como "el más audaz de nuestros músicos" 113 . De Óscar Esplá interpretó "Cenicienta”, la cuarta pieza de las juveniles Impresiones musicales publicada por la Revista Musical Hispanoamericana en 1917 y que el músico alicantino escribió en 1905 para una fiesta de niños ${ }^{114}$. A juicio de Diego, era "una obra tan perfecta y tan original en donde ya se acusaban peculiaridades de su estilo posterior [...], unos cuadros donde el folklore de su Levante alterna con la más personal creación armónica y melódica en pequeñas piezas que parecen resucitar el lirismo íntimo de Schumann y el poético colorido de Grieg, en un lenguaje musical moderno y español" 115 .

La primera parte concluyó con la interpretación de un par de los entonces inéditos Preludios vascos del Padre Donostia y la también inédita "Danza" de la Suite montañesa escrita por el discípulo santanderino de Turina, Antonio de Gorostiaga, ejemplos todos ellos de la utilización de cantos populares en la composición contemporánea ${ }^{116}$. La presentación de la obra inédita de Gorostiaga, responsable en aquellos años de la Sección de Música del Ateneo de Santander, testimonia, además, su estrecha amistad con Diego, pues fue el primero a quien consultó su idea de parafrasear los Nocturnos ${ }^{117}$. Y fue, precisamente en el Ateneo de Santander, el 16 de mayo de 1919, donde Diego ofreció su primera conferencia y recital sobre los Nocturnos de Chopin:

Mi primera conferencia sobre música la di en Santander.Después he dado muchas. Ya son casi incontables. En Soria, en Segovia, en Gijón, siguiendo mi itinerario de profesor de Institutos provincianos: en Cádiz, en Madrid, en Portugal, en Filipinas, en América (Ramiro de Maeztu, entonces embajador de España, presidió un concierto mío en Buenos Aires), en Ateneos, Filarmónicas, Institutos y Universidades ${ }^{118}$.

113 Ibid.

114 Óscar Esplá: "Cenicienta” (cuatro páginas musicales), Revista Musical Hispano-Americana, enero 1917, pp. 9-12. El archivo musical de Gerardo Diego conserva un ejemplar de este volumen. Véase A Benavides: Gerardo Diego y la música..., p. 283.

115 Estas palabras, que podrían haber ilustrado la sesión en el Ateneo, fueron pronunciadas en la conferencia "Música infantil" ofrecida en Buenos Aires en octubre de 1928, en la que también interpretó Kaleidoscope de Goossens, Childern's Corner de Debussy o la Pavana de Ravel. G. Diego: "Música infantil" [Conferencia-concierto, Club Español de Buenos Aires, 28-10-1928], Gerardo Diego. Prosa Musical $1 \ldots$, p. 75

116 El archivo personal de Gerardo Diego conserva los manuscritos musicales de dos obras de Gorostiaga: la mencionada Suite montañesa -compuesta de Preludio, Canción y Danza- y la obra Canto popular y zortzico, fechada en 1918. También conserva una copia manuscrita de "Canción del pastor joven” del Padre Donostia. Véase A. Benavides: Gerardo Diego y la música..., pp. 288, 302.

117 G. Diego: "Historia de una paráfrasis", Panorama poético español, 4-9-1970, Gerardo Diego. Prosa musical I..., p. 314.

118 José María Claver: "Media hora con el pianista Gerardo Diego", Escorial, XX, 1949, p. 1240. Citado en A. Benavides: "Gerardo Diego. Un artista...", p. 99. 
Una gran parte de estas "incontables" conferencias estuvieron dedicadas a la vida y obra de Manuel de Falla. En Soria, además de la Danza ritual del fuego, "de ambiente gitano, originalísimos de armonía y de una fineza rítmica verdaderamente prodigiosa" 119 , el literato santanderino también interpretó las famosas Cuatro piezas españolas. Influenciado por el discurso crítico que Salazar había empezado a fraguar en sus escritos acerca del nacionalismo, diferenciando entre nacionalismo "esencial" y nacionalismo "aparente" basado en la utilización pintoresca de elementos folklóricos ${ }^{120}$, Diego se atrevió a afirmar del compositor gaditano que su arte musical es de "construcción perfecta, popularismo, no externo sino esencial y profundo, riqueza de ritmo y armonía, tales son las mejores cualidades de sus obras que demuestran siempre una potente personalidad" 121 . Estas palabras anticipan la asunción del magisterio falliano que apelaba por la renovación del lenguaje musical -o poético en el caso de Diego- en directa conexión con la vanguardia sin dejar de lado el canto popular. Un hecho que se materializará a lo largo de la década de los veinte, cuando, y teniendo como epicentro la Residencia de Estudiantes, una nueva generación "cumulativa” de artistas e intelectuales asumió los logros de sus predecesores, incorporó la música al proceso de renovación y protagonizó la considerada como Edad de Plata de la cultura española de la que Gerardo Diego fue actor imprescindible como miembro de la "Generación del 27".

\section{Conclusiones}

En el curso de "Historia de la música para piano" celebrado en el Ateneo de Soria, Gerardo Diego se autoimpuso la tarea de comunicar la literatura pianística de Frescobaldi a Falla en trece sesiones a lo largo de apenas tres meses y medio. Como recordaba La voz de Soria, su permanencia en la ciudad "contribuyó notablemente a elevar el nivel de nuestras charlas" 122 y ayudó a la consolidación del proyecto cultural del Ateneo. No obstante, este curso representó un hecho aislado, aunque no por ello menos importante, en la presencia de corrientes musicales vanguardistas en las actividades musicales de la ciudad durante el primer tercio del siglo XX. Por ello, la relevancia de estas trece conferencias-concierto traspasa los límites del Ateneo soriano.

119 "Ateneo de Soria. Historia de la música de piano", AvN, Soria, 8-6-1921, p. 2.

${ }^{120}$ Estas categorías críticas han sido revisadas recientemente en Elena Torres Clemente: "El "nacionalismo de las esencias': ¿una categoría estética o ética?", Discursos y prácticas musicales nacionalistas (1900-1970), Pilar Ramos López (ed.), Logroño, Universidad de la Rioja, 2012, pp. 27-51.

121 "Ateneo de Soria. Historia de la música de piano", AvN, Soria, 8-6-1921, p. 2.

122 "Gerardo Diego", La Voz de Soria, 16-6-1925, p. 1. 
El programa de estas conferencias-concierto no puede entenderse sin la extraordinaria coyuntura fraguada durante sus años de formación en Bilbao y Madrid, donde convergió el bagaje musical adquirido de manera autodidacta, savia constante para su actividad poética juvenil, y la red de contactos establecida con figuras de la máxima relevancia en el panorama musical español del momento, como Manuel de Falla y Adolfo Salazar, quienes le facilitaron el acceso a sus obras de mayor actualidad y a través de quienes conoció las tendencias más vanguardistas irradiadas desde centros cosmopolitas como Madrid. Asumió la modernidad musical y la trasladó a su "Historia de la música de piano" no solo a través de la programación del repertorio contemporáneo afin a sus ideas estéticas, sino también a través de la propia concepción histórica del ciclo, en el que música antigua y contemporánea -tradición y vanguardia- se dan la mano. Además de potenciar el carácter didáctico del ciclo, esta asimilación del formato del concierto histórico basado en la conferencia-concierto que Diego conoció a través de Joaquín Nin, entre otros, le permitió legitimar la inclusión de la música española dentro del repertorio pianístico y proponer también su propia visión de ese repertorio en el que destacó la aportación de compositores como J. S. Bach, Beethoven, Chopin, Debussy, Ravel y Falla, a quienes dedicó sesiones exclusivas o segundas partes enteramente dedicadas a analizar su contribución.

En definitiva, y a pesar de ser una "obra de juventud", la excepcionalidad de estas trece sesiones revela a Gerardo Diego como un gran poeta a la par que un gran pianista y musicógrafo cuando tan solo contaba con veinticuatro años, ilustra la estrecha vinculación que el literato santanderino estableció entre música y poesía a lo largo de toda su vida y cimienta, desde el punto de vista del repertorio, la agenda musical desarrollada por Diego durante décadas desde el punto de vista creador, crítico, pianístico y comunicador. 


\section{Apéndice 1}

Programa del curso de "Historia de la música para piano", por Gerardo Diego. Ateneo de Soria, $1921^{123}$

\begin{tabular}{|c|c|c|c|c|}
\hline & Fecha & Época & Título & Programa \\
\hline 1 & $\begin{array}{l}15-2-1921 \\
18: 30\end{array}$ & Clavecinistas & $\begin{array}{l}\text { Clavecinistas } \\
\text { italianos, } \\
\text { alemanes y } \\
\text { franceses }\end{array}$ & $\begin{array}{l}\text { [Domenico] Scarlatti: Fuga del gato, K.30 } \\
\text { [Girolamo] Frescobaldi } \\
\text { [Michelangelo] Rossi } \\
\text { [Francesco Durante] } \\
\text { [Johann] Kuhnau } \\
\text { [Georg Friedrich] Händel } \\
\text { [Jean-Baptiste] Lully } \\
\text { [Louis-Claude] Daquin }\end{array}$ \\
\hline 2 & $\begin{array}{l}19-2-1921 \\
18: 30\end{array}$ & Clavecinistas & $\begin{array}{l}\text { F. Couperin y } \\
\text { J. P. Rameau }\end{array}$ & 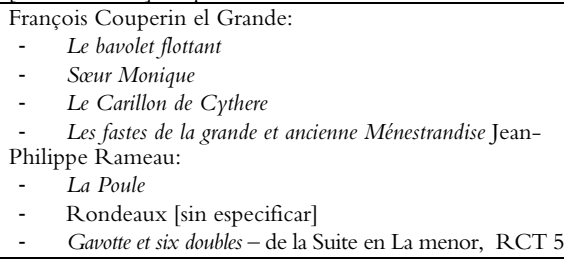 \\
\hline 3 & $\begin{array}{l}26-2-1921 \\
18: 30\end{array}$ & Clavecinistas & $\begin{array}{l}\text { Juan Sebastián } \\
\text { Bach }\end{array}$ & $\begin{array}{l}\text { Preludios [sin especificar] } \\
\text { Suite inglesa [sin especificar] } \\
\text { Concierto italiano, BWV } 971\end{array}$ \\
\hline 4 & $\begin{array}{l}05-3-1921 \\
18: 30\end{array}$ & La sonata clásica & $\begin{array}{l}\text { La sonata clásica: } \\
\text { Mozart }\end{array}$ & $\begin{array}{l}\text { [Joseph] Haydn } \\
\text { [Wolfgang Amadeus] Mozart } \\
\text { [Muzio] Clementi }\end{array}$ \\
\hline 5 & $\begin{array}{l}12-3-1921 \\
18: 30\end{array}$ & La sonata clásica & Beethoven & $\begin{array}{l}\text { Sonata } \mathrm{n} .{ }^{\circ} 8 \text { en Do menor, op. } 13 \text { "Patética" } \\
\text { Sonata n. }{ }^{\circ} 23 \text { en Fa menor, op. } 57 \text { "Appassionata" } \\
\text { Sonata } \mathrm{n} .{ }^{\circ} 31 \text { en La bemol mayor, op. F110 }\end{array}$ \\
\hline 6 & $\begin{array}{l}17-3-1921 \\
18: 00\end{array}$ & Los románticos & $\begin{array}{l}\text { Schubert, } \\
\text { Weber y } \\
\text { Mendelssohn }\end{array}$ & $\begin{array}{l}\text { [Franz] Schubert: } \\
-\quad \text { Impromptus [sin especificar] } \\
-\quad \text { Moments musicaux [D. 780, op. 94] } \\
\text { [Carl Maria von] Weber } \\
-\quad \text { Tema y variaciones sobre un aire ruso, op. } 40 \\
\text { [Felix] Medelssohn } \\
-\quad \text { Fantasias, op. } 16 \\
-\quad \text { Romanzas sin palabras } \text { [selección] }\end{array}$ \\
\hline 7 & $\begin{array}{l}16-4-1921 \\
18: 30\end{array}$ & Los románticos & Frédéric Chopin & $\begin{array}{l}\text { Mazurcas [sin especificar] } \\
\text { Preludios [sin especificar] } \\
\text { Polonesas [sin especificar] } \\
\text { "Marcha fúnebre" - de la Sonata n. }{ }^{\circ} 2 \text {, en Si bemol } \\
\text { menor op. } 35\end{array}$ \\
\hline 8 & $\begin{array}{l}23-4-1921 \\
{[18: 30]}\end{array}$ & Los románticos & $\begin{array}{l}\text { Schumann, Liszt } \\
\text { y Franck }\end{array}$ & $\begin{array}{l}\text { [Robert] Schumann: } \\
\text { - Carnaval, op. } 9 \\
\text { [Franz] Liszt: } \\
\text { - Eglogue - de Années de pèlerinage. Première année: } \\
\text { Suisse. } \\
\text { - Sposalizio (inspirado en Los desposorios de la Vírgen } \\
\text { de Rafael) - de Années de pèlerinage. Deuxième } \\
\text { année: Italie. } \\
\text { Sonetto del Petrarca [sin especificar] - de Années de } \\
\text { pèlerinage. Deuxième année: Italie. } \\
\text { Las fuentes de la Villa d'Este - de Années de } \\
\text { pèlerinage. Troisième année. } \\
\text { [César] Franck } \\
\text { - Coral para órgano [sin especificar] }\end{array}$ \\
\hline
\end{tabular}

${ }^{123}$ Fuentes: El Avisador Numantino 9-2-1921/8-6-1921 y As. S. "La vida musical. Algunas nuevas obras españolas. Un curso de historia de la música de piano", El Sol, Madrid, 4-9-1921, p. 3. 


\begin{tabular}{|c|c|c|c|c|}
\hline 9 & $\begin{array}{l}\text { 30-4-1921 } \\
19: 00\end{array}$ & $\begin{array}{l}\text { Música } \\
\text { moderna }\end{array}$ & $\begin{array}{l}\text { El nacionalismo: } \\
\text { Grieg y los rusos }\end{array}$ & $\begin{array}{l}\text { [Eduard] Grieg: } \\
\text { - Piezas líricas [sin especificar] } \\
\text { - Danzas noruegas, op. } 35 \text { [sin especificar] } \\
\text { [Modest] Mussorgsky: } \\
\text { - Cuadros de una exposición } \\
\text { - Gopak } \\
\text { [Alexander] Borodin: } \\
\text { - Mazurca y Serenata - de la Petite Suite } \\
\text { - Scherzo } \\
\text { [Alexander] Scriabin } \\
\text { - Preludios [selección] }\end{array}$ \\
\hline 10 & $\begin{array}{l}7-5-1921 \\
19: 00\end{array}$ & $\begin{array}{l}\text { Música } \\
\text { moderna }\end{array}$ & Claude Debussy & $\begin{array}{l}\text { "La Soirée dans Granade" - de Estampes } \\
\text { L'isle joyeuse } \\
\text { "The Little Shepherd" (el Zagalillo) y "Golliwogg's } \\
\text { Cakewalk" - de The Children's Corner } \\
\text { "Des pas sur la neige" y "Minstrels" - de Préludes I } \\
\text { Suite Bergamasque }\end{array}$ \\
\hline 11 & $\begin{array}{l}14-5-1921 \\
{[19: 00]}\end{array}$ & $\begin{array}{l}\text { Música } \\
\text { moderna }\end{array}$ & $\begin{array}{l}\text { Música } \\
\text { contemporánea: } \\
\text { europeos }\end{array}$ & 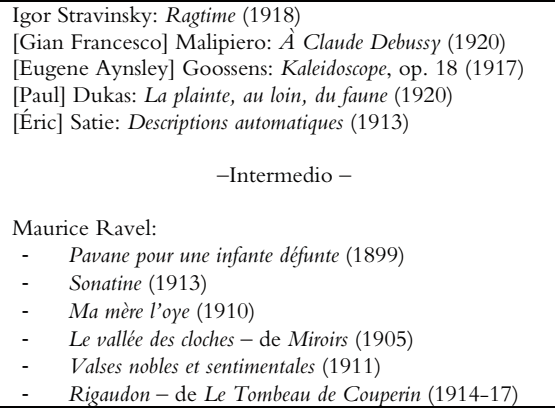 \\
\hline 12 & $\begin{array}{l}21-5-1921 \\
19: 00\end{array}$ & $\begin{array}{l}\text { Músicos } \\
\text { españoles }\end{array}$ & $\begin{array}{l}\text { Clavecinistas - } \\
\text { Albéniz, } \\
\text { Granados, } \\
\text { Usandizaga }\end{array}$ & $\begin{array}{l}\text { Isaac Albéniz: } \\
\text { - } \quad \text { "Castilla" - de Suite Española n. }{ }^{\circ} 1 \text {, op. } 47 \text { (1886) } \\
\text { - } \quad \text { "Evocación" - de Suite Iberia I (1906) } \\
\text { - } \quad \text { "Almería" - de Suite Iberia II (1906) } \\
\text { - } \quad \text { "El Albaicín" - de Suite Iberia III (1907) } \\
\text { Enrique Granados: } \\
\text { - "El fandango del candil" - de Goyescas (1911) } \\
\text { José M. M. Uzandizaga: } \\
\text { - En la aldea están fiesta (1914) } \\
\text { - Preludio y Romería de Mendi-Mendiyan (1909-10) - } \\
\text { arreglo para piano de G. Diego }\end{array}$ \\
\hline 13 & $\begin{array}{l}30-5-1921 \\
19: 00\end{array}$ & $\begin{array}{l}\text { Músicos } \\
\text { españoles }\end{array}$ & $\begin{array}{l}\text { Músicos } \\
\text { españoles } \\
\text { contemporáneos }\end{array}$ & $\begin{array}{l}\text { Joaquín Turina: } \\
\text { - Sonata Romántica, op. } 3 \text { (1909) } \\
\text { Oscar Esplá: } \\
\text { - "Cenicienta" - de Impresiones musicales, op. } 2 \\
\text { Adolfo Salazar: } \\
\text { - Tres preludios para piano (1916) } \\
\text { P. San Sebastián: } \\
\text { - "Eresia" (Canción triste) y "Artzai gaztearen } \\
\quad \text { oiuak" (Canción del pastor joven) - de Preludios } \\
\text { Vascos } \\
\text { Antonio de Gorostiaga: } \\
\text { - Danza - de la Suite montañesa (1917, inédita) } \\
\quad \text {-Intermedio - } \\
\text { Manuel de Falla: } \\
\text { - Cuatro piezas españolas (1909) } \\
\text { - Danza Ritual del Fuego - de El amor brujo (1915, } \\
\text { arreglo para piano) }\end{array}$ \\
\hline
\end{tabular}

